\title{
Percepções e vivências do luto infantil: uma revisão narrativa
}

\author{
da literatura brasileira
}

\section{Perceptions and experiences of child mourning: a narrative review of brazilian}

\author{
literature
}

\section{Glenda Ramos Ebert de Mello' Louizia Pinto Lima ${ }^{1}$ Daniela Cristina Belchior Mota ${ }^{1}, 2$}

\author{
${ }^{1}$ Centro Universitário de Valença (UNIFAA) - \\ Valença $(R J)$ \\ 2 Universidade Federal de Juiz de Fora (UFJF) - \\ Juiz de Fora (MG)
}

\section{Autor correspondente:}

Louizia Pinto Lima

E-mail: louizialima@hotmail.com

\section{Como citar este artigo:}

MELLO, G.R.E.; LIMA, L.P.; MOTA, D.C.B. Percepções e vivências do luto infantil: uma revisão narrativa da literatura brasileira. Revista Saber Digital, v. 14, n. 1, p. 70-88, 2021.

Data de Submissão: 04/12/2020

Data de publicação: 03/05/2021

\section{RESUMO}

O presente artigo buscou sistematizar o conhecimento acerca do luto infantil. Identificar como se dá a elaboração do luto no período da infância, além de verificar possíveis sintomas e quais fatores influenciam em sua elaboração. Baseando-se na literatura brasileira, foi realizada uma revisão narrativa, a partir de uma busca eletrônica nas bases de dados Scielo e Lilacs. Utilizou-se os seguintes descritores para a pesquisa: "luto" (and) "infância" e "luto" (and) "criança". Os critérios de inclusão foram artigos brasileiros correspondentes ao tema da vivência do luto pela criança, o ano de publicação dos artigos não foi utilizado como critério. Observou-se na cultura ocidental um forte silenciamento no que diz respeito ao luto e a morte, principalmente no que tange o universo infantil. Sendo necessário compreender essa experiência como natural a existência humana, e não patologizá-la. Diante dos resultados nota-se uma necessidade de maiores estudos na área a fim de desenvolver diretrizes que possam embasar o manejo de tal momento, não somente no campo da Psicologia como também em equipes multidisciplinares e áreas correlatas.

Palavras-chave: experiência, morte, infância.

\section{ABSTRACT}

This article's aim is to systematize the knowledge about childhood mourning, to identify how it works, as well as to verify possible symptoms and what factors influence its development. Based on Brazilian literature, a narrative review was carried out, based on an electronic search in the Scielo and Lilacs databases. The following descriptors were used for the research: "mourning" (and) "childhood" and "mourning" (and) "child". The inclusion criteria were Brazilian articles corresponding to the theme of the experience of mourning for children; the publication year of the articles wasn't used as criteria. It's been noticed a strong silence in Western culture with regard to grief and death, especially with regard to the children's universe. Therefore it is necessary to understand this experience as natural to the human existence, and not to pathologize it. In view of the results, it is observed a need for further studies in the area in order to develop guidelines that can form a base to the management of such a moment, not only in the field of Psychology but also in multidisciplinary teams and related areas.

Keywords: experience, death, childhood. 


\section{INTRODUÇÃO}

Resta esse constante esforço para caminhar dentro do labirinto

Esse eterno levantar-se depois de cada queda

Essa busca de equilíbrio no fio da navalha Essa terrível coragem diante do grande medo, e esse medo Infantil de ter pequenas coragens.

(VINICIUS DE MORAES, 2004, "O haver")

$\mathrm{Na}$ cultura contemporânea ocidental, em geral as questões suscitadas pela morte trazem consigo certa angústia e rejeição, ainda que esta seja esperada em algum momento da vida. O enfrentamento da própria finitude é algo considerado popularmente como indesejável, fazendo com que o tema só seja abordado quando ocorre o falecimento de alguém próximo. Após o ocorrido, geralmente o assunto não se torna objeto de diálogo e volta ao lugar obscuro e quase intocável que habitava antes. (SENGIK; RAMOS, 2013)

No que se refere especificamente à infância, obstáculos ainda maiores surgem quando as crianças estão envolvidas de alguma forma no enfrentamento da morte, e consequentemente no processo de luto. As crianças por sua vez, nem sempre foram vistas da mesma forma. A concepção de infância que temos hoje foi construída historicamente. Segundo Ariès (1978), na idade média a infância era apenas um período transitório, que não criaria memórias, a sociedade então tratava crianças como "adultos pequenos". Após esse período, foi com a mudança de valores sociais a partir do século XIX que a infância passa aos poucos a ser encarada como parte de um ciclo de vida, que demandava cuidados e proteção. Por sua vez, essa mesma concepção afasta atualmente a criança de temas como a morte, numa tentativa extrema de resguardamento (FERNANDES, 2013 apud CARVALHO; CARVALHO, 2019).

Ariès (1978) ainda contribui ao dizer que a inocência infantil parte na verdade dos adultos, que se sentem na obrigação moral de protegê-las das "sujeiras da vida", essas no século XIX, eram representadas pelo sexo e a partir do século $X X$, pela morte. Assim sendo, o tabu em relação à morte passou a compartilhar juntamente com o tabu sexual, o status de um assunto que não 
deveria ser abordado com as crianças (CARVALHO; CARVALHO, 2019). Assim como os tabus se desenvolvem social e historicamente, as concepções de morte e de infância também se transformaram no decorrer do tempo. Nesse sentido, Ariès (2012) narra que, assim como na Idade Antiga, durante a Idade Média os conceitos de morte e luto eram entendidos de forma mais livre. Suas representações passavam por exageradas manifestações de dor cercadas pela teatralidade, o que acabou por proporcionar a familiaridade social com o tema. Porém, uma mudança brusca no entendimento da sociedade acerca da morte, tornou o luto na Idade Moderna sinônimo de reclusão, dando grande importância aos rituais e ao período do luto.

Já na Idade Contemporânea é possível ver que a morte e o luto passam a ser cada vez mais silenciados, tendo o século XX como um marco histórico deste fenômeno. Segundo Ariès (1977) apud Silva et. al (2012), a morte passa a ser vista como um sinal de fracasso e passa a ser ocultada cada vez mais, sendo transferida aos hospitais, afastando então, as pessoas de seus entes queridos em seus momentos finais. Esta cosmovisão de morte como fracasso é corroborado por Kubler-Ross (2017), que afirma que enquanto sociedade, quanto mais caminhamos cientificamente, mais tememos e negamos a morte. Todo o controle proporcionado pela ciência, e principalmente pela medicina afasta cada vez mais o ser humano da única experiência da qual ele tem certeza. A extensão da vida individual atua nesse cenário como principal fator contribuinte para o adiamento da morte e sua transformação em tabu, prosseguida inevitavelmente de um silenciamento social.

Lima e Kovács (2011) ainda explicitam o interessante paradoxo contemporâneo em que, mesmo que morte seja esse assunto interdito, ela também permeia diversos meios de comunicação de forma massiva e até mesmo banalizadora de tal evento. As crianças que são poupadas dos rituais têm acesso a essa realidade de forma diária e repetitiva dentro de suas casas. Os estudos de Nunes et. al (1998) apud Silva et. al (2012) corroboram à medida em que afirmam que as apresentações de morte, sejam expostas por meio de 
pessoas ou pela televisão, são recebidas e assimiladas pelas crianças e até mesmo reproduzidas em seus desenhos nas idades entre 6 e 7 anos, por exemplo.

A ocorrência do silenciamento é confirmada por diversos autores, Mello e Valle (2004) apontaram tal fenômeno como "Conspiração do Silêncio", que nos traz uma interessante reflexão sobre essas interações sociais que ficam engessadas por essa cultura, sendo esse fator uma grande dificuldade na relação dos adultos com as crianças nesse momento delicado, podendo perturbar a elaboração do luto. Diante de toda a construção histórica ocidental apresentada, apoiando-se em Franco e Mazorra (2007), é importante o incentivo da expressão de sentimentos e exposição da verdade sobre os acontecimentos, embora os adultos erroneamente acreditem que as crianças não são capazes de compreender tal fato (ANDRADE; MISHIMA-GOMES; BARBIERI, 2018). Porém, é evidenciado em pesquisas que a comunicação clara fortalece vínculos e a adaptação diante do ocorrido (WALSH; MCGOLDRICK, 1998 apud LIMA; KOVÁCS, 2011).

Compreendemos luto como um processo no qual a pessoa se reestrutura e se reorganiza diante de sua perda, sendo então, um desafio multidimensional, apresentando-se nos âmbitos cognitivo e emocional (FRANCO; MAZORRA, 2007). Apoiando-se em Bowlby (1990) apud Carvalho e Carvalho (2019) afirmam que esse momento é permeado de sentimentos relativos ao desamparo, aflição e ansiedade de separação. Não sendo apenas ligado à morte, o luto pode representar diversas outras perdas, tais como relacionadas às frustrações do dia a dia, separações ou adoecimentos. Nesse sentido, a abordagem do luto infantil pode configurar-se como um grande desafio diante de tantos aspectos.

Baseado em uma revisão da literatura brasileira, o presente estudo objetivou sistematizar o conhecimento acerca do luto a partir da perspectiva das crianças, identificando como se dá a elaboração do luto na infância, os possíveis sintomas, os fatores influentes na sua elaboração e como tais fatores repercutem no universo infantil. 


\section{MÉTODO}

As revisões de literatura classificadas como revisão narrativa visam à compreensão de determinado tema de estudo, possibilitando descrever e discutir de forma abrangente o seu desenvolvimento ou o "estado da arte". Embora não possuam metodologia que permita a reprodução dos dados ou a construção de respostas quantitativas para questões específicas, as revisões narrativas permitem ao leitor atualizar o conhecimento sobre uma temática específica, adquirindo uma visão crítica (ROTHER, 2007).

Para a realização da presente revisão narrativa, consideramos as bases de dados Scielo e Lilacs, as quais possibilitaram a pesquisa de estudos científicos com relação ao tema de luto infantil. As bases de dados foram consultadas no período de junho de 2020 a agosto de 2020, sendo utilizados os descritores "luto" (and) "infância" e "luto" (and) "criança". Os estudos foram buscados individualmente em "todos os índices" (all indexes). Foram selecionados os trabalhos que eram brasileiros e correspondiam ao tema da vivência do luto na infância, sendo então, excluídos artigos que não eram publicações brasileiras ou não falavam da vivência do luto infantil além de artigos que mesmo presentes nas bases de dados, não estavam disponíveis para a leitura. Para a formulação dos resultados, os estudos foram lidos integralmente e analisados criticamente.

\section{RESULTADOS}

Nas buscas nas bases de dados foram encontradas 15 publicações brasileiras. A tabela 1 "Publicações brasileiras sobre luto e perda na infância" apresenta o título dos estudos, seus autores, referenciais teóricos, tipo de estudo e os objetivos dos respectivos artigos.

Como explicitado na Tabela 1, o período das publicações abarcou os anos entre 2004 e 2019. Um outro aspecto relevante foi a prevalência de artigos 
caracterizados como pesquisas qualitativas, fato esse que hipoteticamente pode ser atribuído à subjetividade do tema. Outro fator em destaque é a predominância de estudos psicanalíticos, evidenciando uma maior participação acadêmica da psicanálise no que envolve o tema do luto infantil. Ademais, em sua maioria, os artigos objetivam a compreensão do fenômeno da morte pela perspectiva da criança, e o respectivo silenciamento que pairava sobre o tema em suas vivências familiares.

Como já exposto, a discussão do luto evidenciou esse processo como um momento de reorganização e reestruturação dos sujeitos diante de sua perda caracterizando-se como um desafio multidimensional que abarca os âmbitos cognitivo e emocional. Para além disso, em função da pluralidade de abordagens encontradas nas literaturas, as autoras Franco e Mazorra (2007) apresentaram a visão do luto pela abordagem psicanalítica, proposta por Freud em sua grande obra, Luto e Melancolia (1917), como uma experiência de trabalho de adaptação do ego em função da perda do objeto amado. A sua elaboração, portanto, se refere ao momento em que o investimento libidinal desse objeto gradualmente começa a ser investido em outros objetos, sendo importante salientar que não há uma desvinculação total deste objeto que foi perdido, acontecendo apenas uma ressignificação. 
Percepções e vivências do luto infantil: uma revisão narrativa da literatura brasileira

Mello GRE, Lima LP, Mota DCB

Tabela 1- Publicações brasileiras sobre luto e perda na infância.

\begin{tabular}{|c|c|c|c|c|}
\hline Título do estudo & Autores & Referencial teórico & Tipo de estudo & Objetivo \\
\hline $\begin{array}{l}\text { Lidando com a morte e o Luto por meio do } \\
\text { brincar: a criança com câncer no hospital }\end{array}$ & Almeida (2005) & Não especificado & Pesquisa qualitativa & $\begin{array}{l}\text { Compreender a vivência da criança com } \\
\text { câncer e seu entendimento acerca da } \\
\text { doença e da hospitalização por meio do } \\
\text { brincar. }\end{array}$ \\
\hline $\begin{array}{l}\text { Luto infantil e Capacidade Criativa - A } \\
\text { Experiência de Perderum Irmão }\end{array}$ & $\begin{array}{l}\text { Andrade, Mishima-Gomes e } \\
\text { Barbieri (2018) }\end{array}$ & $\begin{array}{l}\text { Psicanálise } \\
\text { winnicottiana }\end{array}$ & Pesquisa qualitativa & $\begin{array}{l}\text { Abarcar as relações infantis e seus } \\
\text { desdobramentos psicológicos a partir da } \\
\text { perda de um irmão. }\end{array}$ \\
\hline $\begin{array}{l}\text { Morte Repentina de Genitores e Luto } \\
\text { Infantil: Uma Revisão da Literatura em } \\
\text { Periódicos Cientificos Brasileiros }\end{array}$ & Anton e Favero (2011) & Não especificado & Revisão bibliográfica & $\begin{array}{l}\text { Revisar a bibliografia nacional acerca do } \\
\text { luto infantil advindo de mortes repentinas } \\
\text { dos genitores. }\end{array}$ \\
\hline Caminhos na elaboração de um luto & Batistelli (2010) & $\begin{array}{l}\text { Psicanálise } \\
\text { winnicottiana }\end{array}$ & Relato de experiência & $\begin{array}{l}\text { Relatar a elaboração do luto de uma } \\
\text { criança por meio de análise. }\end{array}$ \\
\hline $\begin{array}{l}\text { Infầncia, perda e educação: diálogos } \\
\text { possiveis }\end{array}$ & Carvalho e Carvalho (2019) & Fenomenologia & Pesquisa qualitativa & $\begin{array}{l}\text { Compreender as relações entre infância, } \\
\text { perda e educação. }\end{array}$ \\
\hline $\begin{array}{l}\text { Criança e luto: vivências fantasmáticas } \\
\text { diante da morte do genitor }\end{array}$ & Franco e Mazorra (2007) & Psicanálise & Pesquisa qualitativa & $\begin{array}{l}\text { Compreender as consequências da perda e } \\
\text { luto no universo de fantasias infantil. }\end{array}$ \\
\hline Educadores e a morte & Kovács (2012) & Não especificado & Estudo teórico & $\begin{array}{l}\text { Compreender a morte como pauta do } \\
\text { contexto escolar. }\end{array}$ \\
\hline $\begin{array}{l}\text { Morte na Familia: Um Estudo Exploratório } \\
\text { Acerca da Comunicação à Criança }\end{array}$ & Lima e Kovács (2011) & Não especificado & Pesquisa qualitativa & $\begin{array}{l}\text { Compreender a comunicação entre } \\
\text { familia e criança diante da morte. }\end{array}$ \\
\hline $\begin{array}{l}\text { O luto de uma criança: o processo em } \\
\text { psicoterapia }\end{array}$ & Marin e Gonçalves (2012) & Abordagem sistêmica & Relato de experiência & $\begin{array}{l}\text { Compreender o processo de luto de uma } \\
\text { criança. }\end{array}$ \\
\hline $\begin{array}{l}\text { A criança com câncer em iminência de morte } \\
\text { - Revisão da literatura }\end{array}$ & Melo e Valle (2004) & Não especificado & Revisão bibliográfica & $\begin{array}{l}\text { Compreender a dinâmica entre a criança } \\
\text { com câncer e a iminência de morte. }\end{array}$ \\
\hline Concepçâo de morte na infầncia & Sengik e Ramos (2013) & Psicologia cognitiva & Pesquisa qualitativa & $\begin{array}{l}\text { Relatar por meio de fala de crianças suas } \\
\text { respectivas concepções de morte. }\end{array}$ \\
\hline $\begin{array}{l}\text { As representações da morte e do luto no } \\
\text { ciclo de vida }\end{array}$ & Silva et. al (2012) & Não especificado & Pesquisa qualitativa & $\begin{array}{l}\text { Definir as representaçôes de morte e luto } \\
\text { no decorrer do ciclo de vida. }\end{array}$ \\
\hline $\begin{array}{l}\text { O luto em instituições de abrigamento de } \\
\text { crianças }\end{array}$ & Tinoco e Franco (2011) & Perspectiva etológica & Pesquisa qualitativa & $\begin{array}{l}\text { Identificar fatores de risco e proteção } \\
\text { envolvidos no luto vivenciado em } \\
\text { instituições de abrigamento. }\end{array}$ \\
\hline $\begin{array}{l}\text { Terapia Comportamental Infantil na relação } \\
\text { mãe e filho ante o luto materno - um relato } \\
\text { de caso }\end{array}$ & Tsutsumi e Menezes (2017) & $\begin{array}{l}\text { Terapia Comportamental } \\
\text { Infantil }\end{array}$ & Relato de experiência & $\begin{array}{l}\text { Relatar um atendimento psicoterapêutico } \\
\text { após perda por suicídio com base na } \\
\text { Terapia Analitico-Comportamental }\end{array}$ \\
\hline Visão da Criança sobre a Morte & Vendruscolo (2005) & Não especificado & Pesquisa qualitativa & $\begin{array}{l}\text { Correlacionar literatura a experiências } \\
\text { clinicas infantis acerca da morte. }\end{array}$ \\
\hline
\end{tabular}

Aberastury (1984), conforme levantado por Silva et. al (2012), contribuiu para a visão psicanalítica do luto, ao acrescentar que, ainda que as crianças não possam verbalizar o sofrimento advindo de um estressor como a morte de alguém próximo, as mesmas são capazes de perceber o ambiente ao seu redor e vivenciar o luto. Essa percepção seria simbólica e principalmente expressada por atividades lúdicas como jogos e desenhos.

Autores como Klein $(1970,1996)$, Bowlby $(1960,1993)$ e Winnicott $(2000)$, referidos por Franco e Mazorra (2007), perceberam o pesar do luto já em crianças entre quatro e sete meses de idade, quando o luto se dá por pessoa 
muito próxima ou em caso de separação. A partir dos dezesseis meses de idade, capacidades cognitivas e emocionais estariam disponíveis para elaboração do luto mais próxima da elaboração de um adulto, porém não é possível comparálos, afinal o psiquismo da criança ainda se encontra em formação. A perda de uma figura de vínculo, é então sentida primeiramente como desamparo pela criança, seguida pelo sentimento de saudade, raiva e medo do abandono. Foram estabelecidas então, alguns padrões que caracterizariam fases do luto, as quais podem se diferenciar em relação à duração ou intensidade em cada pessoa.

A primeira fase é chamada de fase de entorpecimento, que pode durar de horas a semanas, com a presença do sentimento de raiva intensa. A segunda fase, a fase de protesto e busca da figura perdida, é caracterizada pela sua duração prolongada (meses ou anos), e pela tentativa de recuperação da pessoa perdida a todo momento. A terceira fase é a da desorganização e desespero, onde apareceriam principalmente sentimentos de tristeza e perda de valor pelas coisas do mundo. Por último, a fase da organização, possibilitaria a aceitação da perda vivida e um talvez recomeço. Todas essas fases, podem compartilhar o sentimento de tristeza e saudade, que são muito comuns em situações de luto (BOWLBY, 1970/1997 apud ANTON; FAVERO, 2011).

As contribuições de Franco e Mazorra (2007) também adentram o universo psicanalítico ao analisar as fantasias elaboradas por crianças que perderam um ou ambos os pais, sendo essas uma forma de expressão do sintoma presente no luto infantil, que objetiva o reajuste de uma realidade insatisfatória. As crianças participantes do estudo em questão tinham entre 3 e 8 anos, e apresentaram variados tipos de fantasia após a morte de um dos genitores. Dentre elas, destacam-se: a fantasia de culpa (onde a criança sentese culpada pela morte); a identificação (tentativa de ocupar o lugar do ente falecido, ou tentar ser como ele); a rejeição (sentir-se abandonado pelo ente falecido) e a castração (perda de interesse e interrupção do desenvolvimento). De acordo com a literatura, há uma hipótese de que a fantasia de culpa é encontrada em todas as crianças que sofrem a perda de um 
dos pais, variando apenas em intensidade (BOWLBY, 1993; WINNICOTT, 1997; WORDEN, 1996 apud FRANCO; MAZORRA, 2007).

Dando continuidade ao levantamento da literatura, torna-se essencial evidenciar a visão cognitiva desse evento perante as crianças. Apoiando-se em Torres (1999), as autoras Sengik e Ramos (2013) destacaram conceitos relacionados a esse fato, sendo estes: irreversibilidade (como alusão ao próprio nome, a não possibilidade de o corpo retornar ao estado anterior), nãofuncionalidade (interrupção das funções necessárias à vida) e universalidade (todos os que estão vivos podem morrer).

Conforme Torres, Guedes, Torres \& Ebert (1991) apud Silva et. al (2012), a representação de morte vai gradualmente evoluindo, conforme 0 desenvolvimento cognitivo e o afetivo emocional se dão. Sobre essa evolução, em um importante estudo, Torres (1978) referenciada por Lima e Kovács (2011), investigou em uma amostra de 183 crianças entre quatro e treze anos de idade, as representações de morte no pensamento infantil, onde a autora foi capaz de identificar três níveis de compreensão sobre este evento de acordo com as fases de desenvolvimento cognitivo. No nível 1, que representam as crianças do subperíodo pré-operacional (compreendendo crianças entre 2 e 7 anos), a autora destacou algumas características presentes nessa fase do pensamento: as crianças não tem um contraste claro sobre seres inanimados e animados e ainda não compreendem a morte com o conceito de irreversibilidade, admitindo a vida no processo de morrer. No nível 2, que compreendem crianças do $1^{0}$ subperíodo de operações concretas (crianças entre 7 e 11 anos), começa a ocorrer então um desenvolvimento na questão que tange os seres animados e inanimados, elas conseguem entender os processos de vida e morte e por isso atribuem o conceito de não funcionalidade a pessoa falecida, conseguem compreender a morte como algo definitivo, embora ainda não saibam dar explicações consistentes sobre o tema. Já no nível 3, que abarcam as crianças do subperíodo operatório formal (de 11 anos até a idade adulta) do desenvolvimento, existe uma concepção clara e bem delineada sobre os seres 
animados e inanimados, já sendo capaz compreender o conceito de universalidade da morte sobre os seres animados (PAPALIA; FELDMAN; MARTORELL, 2013).

Diversas situações cotidianas podem trazer um sentimento semelhante ao suscitado pela morte, como frustrações, brinquedos danificados ou que se perdem, um animalzinho que foge, confronto entre pessoas queridas, entre outras situações, não sendo apenas por morte propriamente dita (Domingues, 1996 apud Almeida, 2005). É importante salientar que o luto não se trata de uma doença, mas os processos familiares podem contribuir para uma adaptação saudável ou não, e a expressão de sentimentos nesse momento é capaz de promover grande apoio (LIMA; KOVÁCS, 2011).

Um fenômeno amplamente discutido dentro da temática do luto infantil é o que alguns autores chamam de "Conspiração do Silêncio" (MELO; VALLE, 2004; LIMA; KÓVACS, 2011). Esse é compreendido como uma omissão coletiva de um evento de morte, pautada em conceitos de infância que visam a proteção extrema da criança quanto a qualquer obstáculo da vida, como já dito por Ariès (1978). Dessa forma a morte é encarada como um assunto que ultrapassa as habilidades de compreensão da criança, e que deveria ser evitado a todo custo como forma de minimizar o sofrimento (GAUDERER, 1987 apud SENGIK; RAMOS, 2013; ANTON; FAVERO, 2011).

Porém, o efeito dessa omissão é o contrário do que popularmente se espera, podendo causar sentimentos de angústia, frustração, desamparo, desesperança e confusão na criança (MELO; VALLE, 2004; SENGIK; RAMOS, 2013). Para Winnicott (1958), como bem apontado por Andrade, MishimaGomes e Barbieri (2018), a ausência de conversas que possam responder as dúvidas naturais da criança, aparece como um fator diretamente ligado a má elaboração do luto. Interferindo na compreensão da morte, e aceitação de suas consequências, como perder alguém para sempre. Portanto, a comunicação com a criança diante da morte de alguém de seu ciclo social, torna-se importante para a elaboração do luto de forma eficaz e saudável. Apesar do senso comum 
defender o contrário, a criança dispõe de todas as habilidades necessárias para lidar com o seu luto, a menos que o silenciamento ocorra ao seu redor (MELO; VALLE, 2004).

Outro fator geralmente negligenciado às crianças diante de uma morte é a participação em rituais como velórios e enterros. Os rituais de despedida são símbolos importantes na elaboração do luto, que facilitam a reconstrução de interações sociais após o falecimento de alguém próximo, além de serem um momento de suporte importante e construtivo nesse processo (BOSS, 2005 apud ANTON; FAVERO, 2011; SCHOEN; BURGOYNE; SCHOEN, 2004 apud LIMA; KOVÁCS, 2011; SCHACHTER apud KOVÁCS, 2012). Para além disso, Zavaschi et al. (2002), conforme citado por Anton e Favero (2011), afirma que se a criança não participar do ritual de morte quando estes são referentes a seus genitores, aumentam-se as probabilidades de sentimento de culpa e depressão na vida adulta. No entanto, poucas são as crianças as quais se oferece a possibilidade de participação nesse momento familiar, tal decisão mais uma vez é embasada na suposição equivocada de que tal evento poderia causar mais sofrimento a criança (LIMA; KOVÁCS, 2011). Dessa forma, mesmo que faltem referências sobre a recomendação da participação da criança em rituais de luto de acordo com sua idade, entende-se que, se essa participação de fato ocorrer, a mesma deve ser consentida pela criança, uma vez que se ofereça informações sobre o evento (TORRES, 1999 apud LIMA; KOVÁCS, 2011).

No que tange o processo de elaboração do luto, a literatura elenca diversos fatores que podem influenciar este momento de forma a tornar este processo mais difícil, sendo alguns relacionados a criança, como: a relação com a pessoa perdida, relação de apego ansioso, ser do mesmo sexo que a pessoa perdida e o momento de desenvolvimento cognitivo e emocional (FRANCO; MAZORRA, 2007). A capacidade de elaborar a perda também conta como um fator intrapsíquico para esta elaboração, conforme Aberastury (1973), Bowlby (1993), Domingos \& Maluf (2003), Guérin (1979), Klein (1996a), Kraus \& Monroe (2005), Nickman \& Normand (1998), Winnicott (1994) e Worden (1996) apud 
Franco e Mazorra (2007). Sobre fatores relacionados à dinâmica familiar, alguns relevantes que cabem ser citados são: como essa família lidou com o evento após a morte da pessoa querida, como as informações foram dadas (de forma clara e verdadeira a respeito dos fatos), se o luto foi compartilhado, exigências, conscientes ou não, sobre a necessidade dessa criança ocupar o lugar da pessoa perdida, relação ambígua com a pessoa perdida e distanciamento após a perda. As circunstâncias em que tal evento se deu também são influentes no processo, caso a criança tenha testemunhado o fato, caso seja um tabu familiar, se houve algum descuido dessa pessoa sobre o evento ou se foi uma morte violenta e ou repentina (FRANCO; MAZORRA, 2007). Mortes violentas foram destacadas por Anton e Favero (2011), como as mais difíceis em questão de elaboração. Como fatores que podem agir de maneira positiva, a expressão de sentimentos é fundamental para família (FRANCO; MAZORRA, 2007). E em eventos traumáticos, Anton e Favero (2011) destacam a necessidade a psicoterapia se fazer presente para a busca de uma elaboração saudável.

Sendo então o encobrimento da verdade um fator que age negativamente na elaboração do luto e na convivência, deve-se questionar quais os desdobramentos que essa má elaboração é capaz de gerar, afinal essa atitude é capaz de fazer emergirem diversos sintomas patológicos (MELO; VALLE, 2004). Diante da revisão da literatura alguns sintomas foram evidenciados por Harris (1991) apud Kovács (2012) tais como, dificuldades no âmbito escolar, problemas de autoestima e ansiedade. Para além dos já citados, Howarth (2011) e Lima e Kovács (2011) apud Andrade, Mishima-Gomes e Barbieri (2018) apontaram problemas no comportamento, problemas alimentares, agressividade, dificuldades em se socializar e comportamento regredido. Também foram encontrados por Torres (1999) apud Lima e Kovács (2011) comportamentos destrutivos e sentimentos de medo e culpa. Essa má elaboração na infância pode, então, perdurar durante toda a vida como um sentimento de que algo não foi resolvido, ocasionando uma sensação de tristeza 
não explicada (PINCUS, 1989 apud ANDRADE; MISHIMA-GOMES; BARBIERI, 2018).

A questão da lembrança e da memória, mostram-se também significativos na finalização do processo de luto, inclusive o infantil, uma vez que auxiliam a elaboração completa desse evento traumático, independentemente da idade da criança no momento da perda. De acordo com Silverman e Worden (1999), mencionados por Lima e Kovács (2011), continuar vivendo não depende do esquecimento da pessoa falecida, e sim, de sua lembrança. Essa deve ser modificada pela criança com ajuda dos adultos, a fim de se obter "paz com o passado". Sendo assim, recomenda-se a manutenção da imagem da pessoa perdida, através de histórias, fotos, vídeos e etc (ANTON; FAVERO, 2011; LIMA; KOVÁCS, 2011).

Cabe aqui enfatizar que a morte e o luto são experiências altamente subjetivas, não sendo possível estabelecer normas referentes a sua vivência. No entanto, Kovács (2002) citada por Sengik e Ramos (2013), afirma que o processo de luto só pode ser considerado encerrado, quando a criança for capaz de internalizar a presença da pessoa perdida ao mesmo tempo em que oferece espaço para a construção de novas relações. Nesse sentido, consegue-se afirmar mais uma vez a importância do momento de luto na infância, ao invés de sua omissão.

\section{DISCUSSÃO}

À luz de toda a revisão da literatura, pode-se compreender na história ocidental como a morte com o passar dos anos foi ganhando o status de tabu e atualmente, possui o mesmo peso. Para além disso, o luto, enfoque da pesquisa, também se mostrou inserido nos rastros dessa concepção. Como já afirmado, o luto se trata de uma experiência altamente subjetiva e de caráter extremamente individual, por se tratar de uma experiência que deriva não somente de fatores intrínsecos, como fatores extrínsecos, sendo importante ressaltar a importância 
de não patologizá-lo ou padronizá-lo, especialmente no caso das crianças, onde o luto pode ser de alta complexidade e muitas das vezes expressando sintomas que podem parecer desconexos com o acontecimento (ANDRADE; MISHIMAGOMES; BARBIERI, 2018). É importante também refletir acerca de quem comunica, pois este também sente tanto quanto a criança e muitas vezes pode se ver tomado por uma sensação de impotência e falta de respostas ou ações. Desta forma, o luto não se trata de uma doença, e sim de um processo natural da existência humana (LIMA; KOVÁCS, 2011).

Portanto, a má elaboração desse luto no período da infância pode ser associada a diversas complicações psicossomáticas, não somente enquanto criança, podendo estender-se também na vida adulta. Nesse sentido, ao analisar os artigos nacionais sobre o tema, verificou-se a falta de um consenso sólido que embase orientações gerais aos responsáveis, professores e profissionais da saúde, os quais podem lidar frequentemente com crianças enlutadas. $\mathrm{O}$ artigo "Morte na família: um estudo exploratório acerca da comunicação à criança"' escrito por Lima e Kovács (2011) é o único, dentre os artigos selecionados de acordo com os critérios de inclusão, que traz recomendações gerais aos cuidadores de uma criança em processo de luto. Citando Torres (1999), Lima e Kovács (2011) elucidam que: é necessária uma boa comunicação com a criança, sempre adequada ao seu nível de compreensão, deixando que ela determine o ritmo e conteúdo da conversa; a participação em rituais deve ser incentivada desde que consentida pela criança; a expressão dos sentimentos advindos do luto devem ser facilitadas; a memória do ente perdido deve ser mantida através de fotos, vídeos e histórias; e por último, estabelecer uma rede de apoio que conte com familiares, amigos e profissionais que possam auxiliar o enfrentamento dessa fase.

A psicoterapia também aparece constantemente como agente importante na elaboração do luto, ajudando no apoio não só à criança, mas também à família, evidenciado assim a importância de estudos sobre o tema e a ampliação de seus resultados e diretivas. A maioria dos casos de luto infantil ocorre 
simultaneamente com o luto de seus cuidadores, o que torna o processo mais complicado no que tange às formas corretas de se lidar com a criança, uma vez que a rede de apoio também se encontra fragilizada. Nesse sentido, a psicoterapia atua como espaço de suporte, promovendo acolhimento, atenção e um espaço para a partilha do sofrimento, evitando que esse seja silenciado (FRANCO; MAZORRA, 2007; ANTON; FAVERO, 2011; FERNANDES; MAIA, 2008 apud ANTON; FAVERO, 2011).

Ter uma rede de apoio presente e que seja capaz de prover acolhimento, se mostrou essencial na busca por uma elaboração e ressignificação saudável do luto infantil. A escola é um espaço de grande impacto na vida das crianças, sendo de extrema importância adentrar com esse tema para dentro dos muros dessas instituições. Segundo os autores Domingos (2003) apud Kovács (2012), foi evidenciado que as escolas ainda enfrentam dificuldades para lidar com 0 tema de morte e faltam evidências sobre trabalhar essas questões nesses espaços, não havendo propostas de cuidado e acolhimento específicas para essas demandas que acontecem não apenas pelo fato ocorrido, mas por meio de mídias que permeiam a vivência dessas crianças. Como forma de inclusão, os autores citam que nas grades escolares o tema seja incluído em matérias como biologia, filosofia, literatura, entre outras. É fundamental que essa discussão tome novos espaços a fim de tornar o tema relevante e promover uma maior conscientização coletiva.

Observou-se que os estudos eram predominantemente psicanalíticos, todavia muitos dos estudos não definiram claramente as abordagens teóricas que os embasaram, configurando um ponto frágil para possíveis discussões. As pesquisas também levantaram uma relevante questão, a da necessidade de se gerar diretrizes para a Psicologia que sejam capazes de nortear o manejo do luto infantil e maiores estudos acerca do tema a fim de desenvolver essa extensa área de estudo, afinal, ao se falar de morte também estamos falando de vida e do acolhimento de quem fica. Para além de diretrizes, um olhar mais atencioso para esses estudos também terá impacto na criação de políticas públicas, 
corroborando com Anton e Favero (2011), o preenchimento dessa brecha existente nos estudos sobre luto pode ajudar no desenvolvimento de medidas preventivas que venham a minimizar os efeitos da má elaboração do luto infantil.

\section{CONSIDERAÇÕES FINAIS}

O presente estudo se propôs a fazer uma revisão da literatura brasileira, sistematizando o conhecimento acerca do luto a partir da perspectiva das crianças, buscando compreender as diversas noções de luto através das abordagens psicológicas e como esse luto é vivido na infância, bem como os fatores que influenciam sua elaboração e possíveis sintomas decorrentes de quando a mesma não é bem sucedida. A relevância desse tema, se dá a partir do momento em que abordamos a morte, e partir disso evidenciamos a vida e os que ficam. Emergindo então a reflexão suscitada pelo processo do luto, que nos relembra a necessidade de acolhimento e compreensão ao sofrimento nesse delicado momento, porém inerente à existência humana, dada a sua irreversibilidade e inevitabilidade. É de suma importância ampliar o debate para a diminuição do tabu, e compreensão da importância de não se patologizar tal momento, sobretudo em relação às crianças que podem ter processos de maior complexidade e necessidade de atenção.

Portanto, a inclusão do tema nas escolas e a quebra do silêncio se faz necessária para a democratização do conhecimento, para que este possa chegar em outras esferas da sociedade e com isso possam ocorrer mudanças na cultura contemporânea no que tange a morte e o luto. Para além disso, a busca por políticas públicas e diretrizes que gerem um consenso geral para Psicologia e o manejo do luto infantil se mostram como um tema em desenvolvimento, necessitando de maiores debates.

Como se pôde verificar, ainda há muito a ser estudado sobre essa questão, dessa forma, novas pesquisas sobre o assunto tornam-se de 
fundamental importância, principalmente a nível nacional, onde verificou-se uma baixa incidência de investigações relacionadas ao luto infantil. Este é um tema muito complexo e que envolve uma dimensão subjetiva, evidenciando a necessidade de estudos focados também nas especificidades e vulnerabilidades vivenciadas pela infância brasileira. Maiores investimentos poderiam ser feitos nas pesquisas do Brasil, visando não só embasar a atuação do psicólogo nesse campo, mas também, proporcionando a divulgação desses saberes a quem atua rotineiramente no manejo do luto, como por exemplo as equipes multidisciplinares em saúde, bem como os educadores, atores-chave desse processo haja vista o vínculo cotidiano com as crianças nas escolas.

\section{REFERÊNCIAS}

ALMEIDA, F. Lidando com a morte e o luto por meio do brincar: a criança com câncer no hospital. Boletim de Psicologia, São Paulo, v.55, n.123, p.149-167, 2005.

Disponível

em: http://pepsic.bvsalud.org/scielo.php?script=sci_arttext\&pid=S000659432005000 200003\&lng=pt\&nrm=iso. Acesso em: 21 jun. 2020.

ANDRADE, M. L.; MISHIMA-GOMES, F. K. T.; BARBIERI, V. Children's Grief and Creativity: The Experience of Losing a Sibling. Psico-USF, Bragança Paulista, v.23, n.1, p.25-36, $2018 . \quad$ Disponível em: https://www.scielo.br/scielo.php?script=sci_arttext\&pid=S141382712018000100 025\&lang=pt. Acesso em: 21 jun. 2020.

ANTON, M. C.; FAVERO, E. Morte Repentina de Genitores e Luto Infantil: Uma Revisão da Literatura em Periódicos Científicos Brasileiros. Interação em Psicologia, Porto Alegre, v.15, n.1, p.101-110, 2011. Disponível em: https://revistas.ufpr.br/psicologia/article/view/16992/16423. Acesso em: 21 jun. 2020.

ARIÈS, P. História da morte no Ocidente: da Idade Média aos nossos dias. Ed especial. Rio de Janeiro: Nova Fronteira, 2012. 290 p.

ARIÈS, P. História Social da criança e da família. Rio de Janeiro: Editora Guanabara S.A., 1978. 279 p. 
BASTISTELLI, F. Caminhos na elaboração de um luto. Jornal de psicanálise, São Paulo, v.43, n.79, p.155-162, 2010. Disponível em: http://pepsic.bvsalud.org/scielo.php?script=sci_arttext\&pid=S010358352010000 200010. Acesso em: 21 jun. 2020.

CARVALHO, E. C.; CARVALHO, L. V. Infância, perda e educação: diálogos possíveis. Psicologia em pesquisa, Juiz de Fora, v.13, n.3, p.73-92, 2019. Disponível em:

http://pepsic.bvsalud.org/scielo.php?script=sci_arttext\&pid=S198212472019000 300004. Acesso em: 21 jun. 2020.

FRANCO, M. H. P.; MAZORRA, L. Criança e luto: vivências fantasmáticas diante da morte do genitor. Estudos de Psicologia, Campinas, v.24, n.4, p.503-511, 2007. Disponível em: https://www.scielo.br/scielo.php?script=sci_arttext\&pid=S0103166X2007000400009. Acesso em: 21 jun. 2020.

KÓVACS, M. J. Educadores e a morte. Revista Semestral da Associação Brasileira de Psicologia Escolar e Educacional, São Paulo, v.16, n.1, p.7181, $2012 . \quad$ Disponível em: https://www.scielo.br/scielo.php?script=sci_arttext\&pid=S1413-

85572012000100008. Acesso em: 21 jun. 2020.

KÜBLER-ROSS, E. Sobre a morte e o morrer. 10. ed. São Paulo: Editora WMF Martins Fontes, 2017. 304 p.

LIMA, V. R.; KÓVACS, M. J. Morte na Família: Um Estudo Exploratório Acerca da Comunicação à Criança. Psicologia: ciência e profissão, Brasília, v.31, n.2, p.390-405, 2011. Disponível em: https://www.scielo.br/scielo.php?script=sci_arttext\&pid=S141498932011000200 014\&lang=pt. Acesso em: 21 jun. 2020.

MARIN, M.; GONÇALVES, N. T. O Luto de uma Criança: O processo em Psicoterapia. Pensando famílias, Porto Alegre, v.16, n.2, p. 53-62, 2012.

MELO, L.; VALLE, E. A criança com câncer em iminência de morte: revisão da literatura. Acta Oncológica Brasileira, São Paulo, v.24, n.3, p. 671-675, 2004. Disponível em: https://accamargo.phlnet.com.br/Acta/AOB200424(3)p.6715.pdf. Acesso em: 21 jun. 2020.

PAPALIA, D. E.; FELDMAN, R. D.; MARTORELL, G. Desenvolvimento Humano. 12. ed. Porto Alegre: AMGH, 2013. 800 p.

ROTHER, E. T. Revisão sistemática $X$ revisão narrativa. Acta Paulista de Enfermagem, São Paulo, v.20 n.2, 2007. Não paginado. Disponível em: 
http://www.scielo.br/scielo.php?pid=S010321002007000200001\&script=sci_artt ext\&tlng=pt. Acesso em: 26 fev. 2020.

SENGIK, A. S.; RAMOS, F. B. Concepção de morte na infância. Psicologia \& Sociedade, Recife, v.25, n.2, p.379-387, 2013. Disponível em: https://www.scielo.br/scielo.php?script=sci_arttext\&pid=S0102-

71822013000200015. Acesso em: 21 jun. 2020.

SILVA. et. al. As representações da morte e do luto nos ciclos de vida. Revista Temática Kairós Gerontologia, São Paulo, v.15, n.4, p.185-206, 2012. Disponível em: http://revistas.pucsp.br/index.php/kairos/article/view/10100/12634. Acesso em: 21 jun. 2020.

TINOCO, V.; FRANCO, M. H. P. O luto em instituições de abrigamento de crianças. Estudos de Psicologia, Campinas, v.28, n.4, p.427-434, 2011. Disponível em: https://www.scielo.br/scielo.php?script=sci_arttext\&pid=S0103166X2011000400003. Acesso em: 21 jun. 2020.

TSUTSUMIA, M. M. A.; MENEZES, A. B. de C. M. Terapia Comportamental Infantil na relação mãe e filho ante o luto materno - um relato de caso. Revista Brasileira de Psicoterapia, Porto Alegre, v.19, n.3, p.53-62, 2017. Disponível em:

https://s3-sa-east-

1.amazonaws.com/publisher.gn1.com.br/rbp.celg.org.br/pdf/v19n3a05.pdf.

Acesso em: 21 de jun. de 2020.

VENDRUSCOLO, J. Visão da Criança sobre a Morte. Simpósio: Morte: valores e dimensões, Ribeirão Preto, v.38, n.1, p.26-33, 2005.

VINICIUS DE MORAES. O haver (poesia). Disponível em: http://www.viniciusdemoraes.com.br/pt-br/poesia/poesias-avulsas/o-haver.

Acesso em: 4 dez. 2020. 